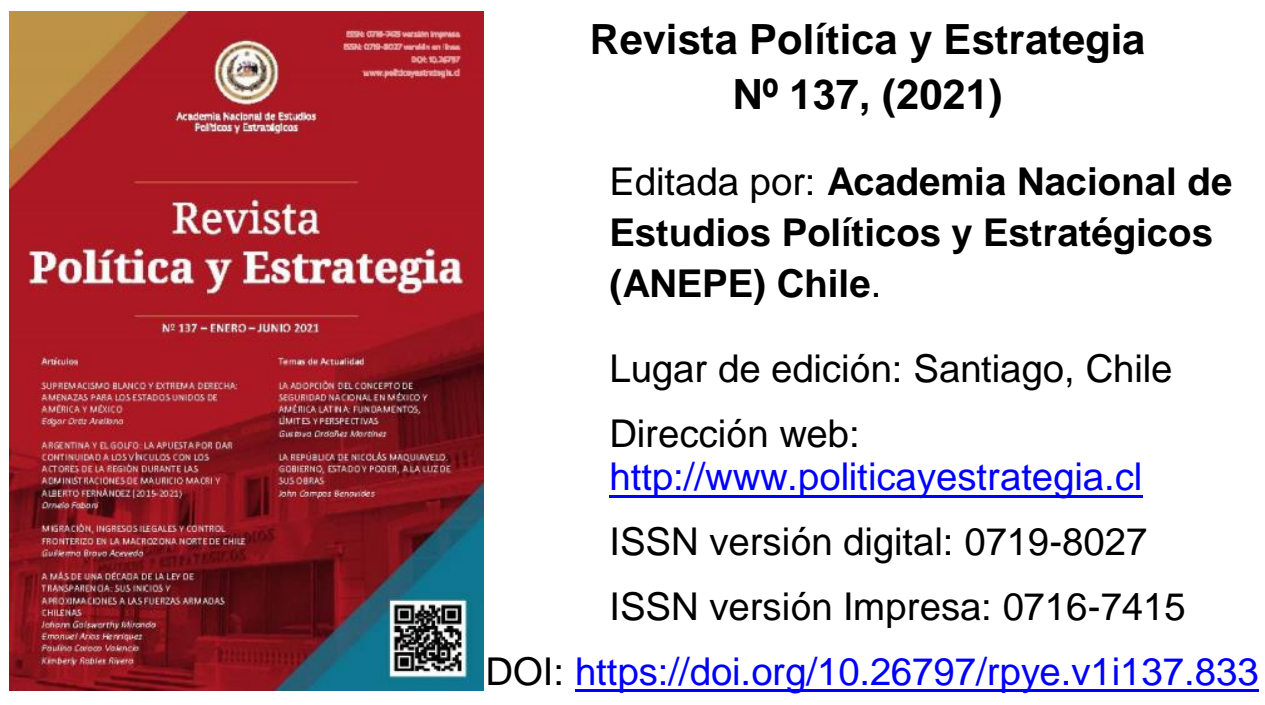

Para citar este artículo / To cite this article: GOLSWORTHY Miranda, Johann, ARIAS Henríquez, Emanuel, CAROCA Valencia, Paulina, ROBLES Rivera, Kimberly: "A más de una década de la Ley de Transparencia: sus inicios y aproximaciones a las Fuerzas Armadas chilenas".

Revista Política y Estrategia No 137. 2021. pp. 93-118

DOI: https://doi.org/10.26797/rpye.v1i137.833

Si desea publicar en Política y Estrategia, puede consultar en este enlace las Normas para los autores:

To publish in the journal go to this link:

http://politicayestrategia.cl/index.php/rpye/about/submissions\#authorGuidelines

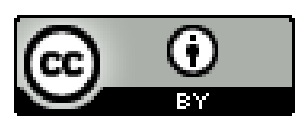

La Revista Política y Estrategia está distribuida bajo una Licencia Creative Commons Atribución 4.0 Internacional 
Revista "Política y Estrategia" № 137, 2021, pp. 93-118

ISSN 0716-7415 (versión impresa) - ISSN 0719-8027 (versión en línea)

Academia Nacional de Estudios Políticos y Estratégicos

A más de una década de la Ley de Transparencia: sus inicios y aproximaciones a las Fuerzas Armadas chilenas

Johann Golsworthy Miranda - Emanuel Arias Henríquez - Pau-

lina Caroca Valencia - Kimberly Robles Rivera

\title{
A MÁS DE UNA DÉCADA DE LA LEY DE TRANSPARENCIA: SUS INICIOS Y APROXIMACIONES A LAS FUERZAS ARMADAS CHILENAS• $\infty$
}

\author{
JOHANN GOLSWORTHY MIRANDA* \\ EMANUEL ARIAS HENRÍQUEZ** \\ PAULINA CAROCA VALENCIA $* * *$ \\ KIMBERLY ROBLES RIVERA****
}

\section{RESUMEN}

El presente artículo es una aproximación al fenómeno reciente, problemático y no natural de la transparencia en los organismos del Estado, así como su compleja relación con el ámbito de la Defensa y Fuerzas Armadas. Se realizará en primera instancia un abordaje teórico sobre la transparencia. Posteriormente, un recuento de los procesos históricos-normativos de Chile en la materia, junto con una revisión de la Ley 20.285 "Sobre acceso a la información pública" de 2008 así como de los cuerpos normativos vinculados a las Fuerzas Armadas y ámbito de la Defensa que limitan su aplicación. A partir de esto, se sostendrá que muchos de los desafíos que enfrentan actualmente las Fuerzas Armadas en materia de transparencia son los desafíos que, transversalmente, deben afrontar los organismos de la Administración Pública.

Palabras clave: Transparencia; información pública; Fuerzas Armadas; reserva; secreto.

- $\quad$ Este artículo es producto de la investigación ANEPE № 202013 "A más de una década desde la implementación y ejecución de la Ley de Transparencia en las Fuerzas Armadas: balances y nuevos desafíos".

* Administrador Público de la Universidad de Santiago de Chile (USACH), Magíster en Ciencias Militares mención Gestión Estratégica de la Academia de Guerra del Ejército y Diplomado en Toma de decisiones Complejas de la Academia Nacional de Estudios Políticos y Estratégicos. Actualmente se desempeña como Encargado de Extensión y Vinculación con el Medio de la Academia Politécnica Militar del Ejército de Chile. johann.golsworthy@gmail.com ORCID: https://orcid.org/0000-0001-8062-2472

** Egresado de la Licenciatura de Estudios Internacionales (USACH). Actualmente se desempeña como Investigador Independiente. emanuel.arhen@gmail.com ORCID: https://orcid.org/0000-0002-8338-206

*** Administradora Pública (USACH) y Diplomada en Compras Públicas de la Universidad del Desarrollo en conjunto con la Academia SUBDERE, actualmente se desempeña como Asesora de Subsistencias en las División de Adquisiciones del Ejército de Chile. paulina.caroca@usach.cl ORCID: https://orcid.org/00000003-4091-9532

**** Administradora Pública (USACH), actualmente se desempeña como Asistente de Asuntos Políticos y Prensa en la Embajada de México en Chile. kimberlyroblesrivera@gmail.com ORCID: https://orcid.org/00000002-1495-2032

$\infty \quad$ Fecha de recepción: 0030920 - Fecha de aceptación: 080621. 


\section{OVER A DECADE OF THE TRANSPARENCY LAW: ITS BEGINNINGS AND APPROACHES TO THE CHILEAN ARMED FORCES ABSTRACT}

This article is an approximation to the recent, problematic and unnatural phenomenon of Transparency in State agencies, as well as its complex relationship with the Defense and Armed Forces field. In the first instance, a theoretical approach to Transparency will be carried out. Subsequently, an overview of the historical-regulatory processes of Chile in the matter, along with a revision of the Law 20.285 "On access to public information" of 2009, as well as the regulatory bodies linked to the Armed Forces and the field of Defense that limits its application. Based on this, it will be argued that many of the challenges currently facing the Armed Forces in terms of Transparency are the challenges that, across the board, Public Administration agencies must face.

Key words: Transparency; public information; Armed Forces; reserve; secret.

\section{HÁ MAIS DE UMA DÉCADA DA LEI DE TRANSPARÊNCIA: SEUS INÍCIOS}

\section{E ABORDAGENS PARA AS FORÇAS ARMADAS CHILENAS RESUMO}

O presente trabalho contém uma abordagem do recente fenômeno, problemático e não natural da Transparência nos organismos do Estado, bem como sua complexa relação com o âmbito da Defesa e Forças Armadas. No primeiro lugar, será feita uma abordagem teórica sobre a Transparência. Logo depois, uma contagem dos processos históricos-normativos do Chile nessa área, junto com uma revisão da Lei 20.285 "Sobre acesso à informação pública" de 2008 e dos corpos normativos vinculados às Forças Armadas e ao âmbito da Defesa que limitam sua aplicação. Com base nisso, será argumentado que muitos dos desafios que as Forças Armadas enfrentam atualmente em termos de Transparência são os desafios que, de forma transversal, os órgãos da Administração Pública devem enfrentar.

Palavras-chave: Transparência; informação pública; Forças Armadas; reserva; segredo.

\section{INTRODUCCIÓN}

En el marco de una Agenda para la Modernización del Estado, se promulga en el año 2008 la Ley № 20.285 sobre Acceso a la Información Pública, conocida como "Ley de Transparencia" (LT), sentando las bases del principio de transparencia de la función pública y del derecho de acceso a la información de los órganos de la Administración del Estado, 
los métodos para hacerlo efectivo y las excepciones al mismo. Entre sus disposiciones, esta ley establece algunas reservas vinculadas a las Fuerzas Armadas (en adelante, FF.AA.), en atención a la importancia de la seguridad y la soberanía de la nación. En ese sentido, resulta interesante estudiar fenómenos relativos a la aplicación de esta ley en las FF.AA., considerando la nueva labor que ésta implicó para los distintos órganos de la administración del Estado, además del plano histórico en el que tomó lugar.

El presente artículo describe el surgimiento de esta ley, así como su desarrollo e implementación vinculado a las FF.AA. Estos organismos representan un sector de la Administración Pública en donde, en circunstancias normales (sin una amenaza latente), resultan de interés secundario para la ciudadanía; y que, además, como sector vinculado a la seguridad, evoluciona de manera más dilatada con relación a otras dimensiones del Estado ${ }^{1}$. Sin embargo, en un contexto donde existe una creciente demanda por transparencia ante distintos actos de corrupción ${ }^{2}$, las FF.AA. han debido modernizar y reestructurar sus procesos, acatando las disposiciones de la LT; de tal manera, esta normativa acoge el secreto o reserva de información de las instituciones del Estado, cuando estas revisten un peligro que pudiera amenazar el bien común y la seguridad de la nación, entre otras, y donde los organismos castrenses son las instituciones del Estado que tienen la mayor cantidad de información que puede ser clasificada como reservada o secreta ${ }^{3}$.

Bajo este orden de ideas, en la primera sección del artículo, se hará una breve revisión teórica ligada a la transparencia, con el fin de identificar los principales postulados en esta materia. La según parte, versará un análisis del panorama internacional, identificando indicadores para conocer la realidad latinoamericana en materia de trasparencia. Posteriormente, en el tercer apartado, se expondrán los motivos que impulsaron a que Chile elaborara la Ley $\mathrm{N}^{\circ} 20.285$, así como los principales hechos que pavimentaron el camino para su incorporación en el cuerpo legislativo chileno. En este contexto, se explicará con una breve reseña la estructura de la ley, y los principales mecanismos que dispone la misma para que los ciudadanos ejerzan los derechos que otorga este cuerpo jurídico. Finalmente, se hará una breve referencia a las condiciones de reserva en las FF.AA., junto con otros cuerpos legislativos.

Considerando lo anterior, más de una década ha pasado desde que Chile inició diversos procesos de modernización del Estado, con el fin de alcanzar una mayor transparencia y generar mecanismos de confianza mutua con las naciones vecinas y con la ciudadanía. En 2020 se cumplieron 11 años desde la plena aplicación de la LT, y bajo este precepto, se pretende describir cómo se ha aplicado este proceso de transparencia y acceso a la información, de manera particular en las FF.AA., señalando su impacto y singularidad legislativa, junto con la forma en la que se le ha dado cumplimiento a esta normativa desde los organismos castrenses: ¿cómo se gestó la ley de transparencia? ¿cuál es la importancia de la LT

1 ÁLVAREZ, Veloso, David. Transparencia y rendición de cuentas en los presupuestos de defensa: del secreto al escrutinio público. Flacso-Chile. Boletín del programa seguridad y ciudadanía No1, 2006. p. 1.

2 Ibíd. p. 2

3 SOUSA O., José. La Experiencia de Chile en la Transparencia y Acceso a la Información: El cambio institucional del Gobierno Central ante las nuevas disposiciones normativas. [en línea]. Tesis (Magíster en Gestión y Políticas Públicas). Santiago, Chile: Universidad de Chile - Facultad de Ciencias Físicas y Matemáticas, 2010. p. 29. 
y su impacto en las FF.AA.?, y ¿̇de qué manera coexiste la LT con los elementos reservados, propios de las FF.AA.?

\section{EL CONCEPTO DE TRANSPARENCIA}

¿Qué es la Transparencia? La respuesta a esta pregunta depende de a quien se le realice y el contexto en que se ejecute. Para fines del presente trabajo y a partir de la revisión bibliográfica, se abordará y desarrollará una definición de transparencia con relación a la Administración del Estado 4 .

La primera consideración que es importante tener presente, es que la transparencia es un elemento no natural, cuyo desarrollo dependerá en primera instancia de la voluntad y posterior existencia de una política y planes claros al respecto, encargados de definir tanto los recursos como las normas necesarias para su funcionamiento. Al mismo tiempo, su conservación y profundización requerirán de la adopción de una cultura organizacional favorable a su ejercicio, la que deberá ser promovida y resguardada de manera constante. A partir de lo dicho, queda también en claro que la transparencia no es simplemente información 5 .

Si bien el concepto de transparencia puede llegar a parecer intuitivo, el mismo ha evolucionado con el tiempo, partiendo de definiciones más bien restringidas, como la de Naesens $s^{6}$, quien la define como "una práctica o instrumento que utilizan las organizaciones para publicar y volver pública cierto tipo de información o bien para abrir al público algunos procesos de toma de decisiones". Yendo un paso más allá, Ugalde define transparencia "como una característica que abre la información de las organizaciones políticas y burocráticas al escrutinio público, mediante sistemas de clasificación y difusión que reducen costos de acceso a la información del gobierno"7. Por su parte Armengol y Schuster, en una definición mucho más amplia del término, pues entienden la transparencia, en el ámbito de la función pública, "como un atributo, una práctica, una garantía legal, un valor organizacional o un elemento que contribuye a fortalecer los valores de la democracia y a incrementar la eficacia en el quehacer gubernamental"s.

Visto lo anterior, se puede afirmar que la transparencia es una acción deliberada ${ }^{9}$ que puede ser desde una cualidad presente en una organización (sea esta o no de carácter gubernamental), hasta un elemento intrínseco y propio del buen ejercicio de lo público en un sistema democrático, eficaz y eficiente, aplicable a todas sus áreas y que se caracteriza por

4 La necesidad de realizar está aclaración se justifica en tanto las posibles diferencias que puedan llegar a haber, como señala Cunill en relación a otros contextos, como lo es el ámbito político, ámbito empresarial, ONG u otro tipo de organizaciones.

5 CUNILL, Nuria. La transparencia en la gestión pública: Cómo construir viabilidad. Estado, Gobierno, Gestión Pública. Revista Chilena de Administración Pública N 8, México. 2006.

6 NAESSENS, Hilda. Ética pública y transparencia. XIV Encuentro de Latinoamericanistas Españoles: Congreso internacional, Sep. 2010, Santiago de Compostela, España.). México. 2010. p. 212.

7 UGALDE, Luis Carlos. Rendición de cuentas y democracia: El caso de México. Instituto Federal Electoral, México. 2002. p. 17.

8 ARMENGOL, Ángel \& SCHUSTER, Juan. Transparencia y rendición de cuentas en el ámbito municipal. Instituto de la Contaduría Pública. Horizontes de la Contaduría No. 1, Universidad Veracruzana. 2014. p.128.

9 lbíd. p. 229. 
A más de una década de la Ley de Transparencia: sus inicios y aproximaciones a las Fuerzas...

la entrega de información por medio de un sistema de clasificación y difusión adecuados, a los demandantes o solicitantes de la misma.

Es menester aclarar que, si bien la transparencia implica el poner a disposición del público información gubernamental potencialmente susceptible de ser revisada, analizada y, en su caso, utilizada como herramienta para sancionar en caso de anomalías, esto equipara al concepto de "Transparencia" al de "Rendición de Cuentas", siendo el primero un parte del sistema global que implica el segundo ${ }^{10}$.

\subsection{Beneficios de la transparencia}

Aguilar ${ }^{11}$, en el contexto de los regímenes democráticos, establece cinco funciones específicas de la transparencia:

- Evaluación de gobernantes: Probablemente la función más conocida de las cinco, es aquella que permite a los ciudadanos castigar o premiar (sin perjuicio de otros canales de información, incluso pudiendo llegar a apoyarlos) el desempeño de autoridades y/o gobernantes.

- Rendición de cuentas: Siendo notablemente asociadas las nociones de Transparencia y Rendición de Cuentas, la primera funciona como uno de los mecanismos para que los gobernantes respondan por aquello que hacen o han dejado de hacer en relación a sus deberes públicos.

- Control del poder público: "A menudo la transparencia ha sido caracterizada como uno de los varios elementos que, en la democracia liberal, limitan al poder del Estado"12, evitando el ejercicio de abusos por parte de políticos y funcionarios, garantizando derechos fundamentales, limitando e incluso inhibiendo la comisión de conductas inadecuadas.

- Fortalecer la autoridad política: Uno de los efectos paradójicos de la Transparencia es que al mismo tiempo que limita el poder de los gobiernos, también es capaz de aumentarlo por medio de la generación de confianza, lo que ayuda a fortalecer la aprobación de las decisiones gubernamentales, mejorando también la relación con los ciudadanos y disminuyendo los costos de transacción.

- Detección y corrección de errores: Esta se trata de una forma particular en que la Transparencia fortalece a los gobiernos: Mejorar de la capacidad cognitiva. Esta mejora se debe a que "la transparencia puede establecer un entramado institucional el cual, si funciona de manera adecuada, facilita que la toma de decisiones sea más concienzuda y hace que sea más sencillo aprender de los errores y corregirlos"13 al ser las instituciones que garantizan el acceso a la información no son

10 UGALDE. Op. Cit. p. 17.

11 AGUILAR, José Antonio. Transparencia y democracia: Claves para un concierto. México. Instituto Nacional de Transparencia, Acceso o la Información y Protección de Datos Personales. México, 2015. pp. 29-30.

12 Ibíd. p. 31.

13 Ibíd. p. 33. 
solamente del interés los ciudadanos, sino que también de otras instituciones y tomadores de decisiones.

Las cinco funciones anteriormente mencionadas no son solo aplicables a los gobiernos dentro de los sistemas democráticos, sino que tanto individual como grupalmente al conjunto de instituciones que conforman el Estado.

\subsection{Problemas para la transparencia}

Al no ser la Transparencia un elemento natural de las organizaciones ${ }^{14}$, su implementación en los sistemas de administración modernos no está exenta de dificultades, pues se habla de una idea a veces extraña para los funcionarios a la que pueden llegar a mostrar rechazo (la exposición no es algo que en general acomode a las personas). A esta dificultad también se debe sumar la falta de experiencia, la cantidad y calidad de recursos existentes, así como el diseño de una adecuada normativa, la ralentización de los trámites burocráticos, el tiempo necesario para que los cambios, la adopción e interiorización de nuevas y mejores prácticas ${ }^{15}$, el costo de elección, mayores niveles de estrés, entre otros factores. "Por eso, la transparencia debe elaborarse, construirse, implementarse cuidadosamente, con una visión de largo plazo que asuma al mismo tiempo diferentes objetivos: legales, reglamentarios, políticos, organizacionales, educativos, culturales, dentro y fuera de las instituciones del Estado"16.

\subsection{Límites de la transparencia: Seguridad y Defensa}

Según Ackerman, el acceso a la información pública puede llegar a facilitar la construcción de un Estado mucho más honesto, eficaz y eficiente en términos generales ${ }^{17}$, de modo que es necesario tener igualmente presente la existencia de organizaciones que, para funcionar correctamente, requieren de algún nivel (mayor o menor) de discreción ${ }^{18}$ respecto a decisiones adoptadas, el contenido de documentos, actos realizados o quiénes han participado en ellos. La apelación a la necesidad de la limitación de la información a causa de los potenciales riesgos que la publicación de la misma puede llegar a significar, no es una novedad, especialmente en asuntos relacionados con la seguridad y/o defensa.

\section{TRANSPARENCIA EN EL ESTADO}

Si bien y como señalan Armengol \& Schuster ${ }^{19}$, existe un amplio consenso (especialmente en el ámbito académico) respecto al rol de la transparencia en la función pública y el fortalecimiento de los valores democráticos, esta relación no ha sido siempre

14 VERGARA, Rodolfo. La transparencia como problema. Cuadernos de Transparencia. Instituto Federal de Acceso a la información Pública México. 2008. p. 5.

15 Ibíd.

16 Ibíd.

17 ACKERMAN, John. Introducción: Más allá del acceso a la información. En: ACKERMAN, John. Más allá del acceso a la información: Transparencia, rendición de cuentas y Estado de derecho. México. Siglo XXI. 2008. p. 11.

18 VERGARA. Op.cit. (2008)

19 ARMENGOL, Ángel \& SCHUSTER. Loc. Cit. 
A más de una década de la Ley de Transparencia: sus inicios y aproximaciones a las Fuerzas...

tan evidente ni tan antigua como pudiera llegar a parecer hoy en día ${ }^{20}$. Mientras que, en la teoría política, la reflexión sobre la importancia y beneficios de la difusión de la información pública no es algo nuevo ${ }^{21}$, su aplicación en el funcionamiento del Estado es una historia diferente.

De acuerdo con los datos publicados por el Global Right to Information Rating (GRIR) hasta 2019, es recién a contar de 1980 que puede comenzar a hablarse de la promulgación casi ininterrumpida de leyes nacionales sobre transparencia. La situación es todavía más llamativa al notar que, es en 1999 que se produce un incremento importante en el número de leyes nacionales publicadas anualmente, siendo la década del 2000 sin lugar a dudas el periodo de mayor producción en la materia.

TABLA N ${ }^{\circ} 1$

Leyes Nacionales sobre TAI publicadas entre 1766 a 2019

\begin{tabular}{|l|c|c|c|c|c|c|c|c|c|c|c|}
\hline Año & 1766 & 1951 & 1966 & 1970 & 1978 & 1982 & 1983 & 1985 & 1986 & 1987 & Total \\
\hline $\mathbf{N}^{\circ}$ de Leyes & 1 & 1 & 1 & 2 & 2 & 2 & 1 & 1 & 1 & 1 & $\mathbf{1 3}$ \\
\hline Año & 1990 & 1991 & 1992 & 1993 & 1994 & 1995 & 1996 & 1997 & 1998 & 1999 & Total \\
\hline $\mathbf{N}^{\circ}$ de Leyes & 1 & 0 & 2 & 1 & 2 & 0 & 3 & 2 & 2 & 6 & $\mathbf{1 9}$ \\
\hline Año & 2000 & 2001 & 2002 & 2003 & 2004 & 2005 & 2006 & 2007 & 2008 & 2009 & Total \\
\hline $\mathbf{N}^{\circ}$ de Leyes & 7 & 2 & 7 & 9 & 5 & 7 & 2 & 6 & 6 & 3 & $\mathbf{5 4}$ \\
\hline Año & 2010 & 2011 & 2012 & 2013 & 2014 & 2015 & 2016 & 2017 & 2018 & 2019 & Total \\
\hline $\mathbf{N}^{\circ}$ de Leyes & 1 & 7 & 1 & 6 & 5 & 4 & 7 & 5 & 5 & 1 & $\mathbf{4 2}$ \\
\hline
\end{tabular}

Elaboración propia a partir de la información disponible en: https://www.rti-rating.org/country-data/

Los datos publicados por GRIR dan cuenta de que la mayoría de Estados que actualmente cuentan con una política nacional sobre transparencia y otros temas relacionados (como derecho de acceso a la información), no tienen más de veinte años de experiencia en la materia. La situación es todavía más llamativa al notar que, de estos, poco menos de la mitad no alcanzan los diez años de experiencia.

Finalmente, a diferencia de otras reivindicaciones fuertemente valoradas por su carácter democrático, la demanda por transparencia no es en primera instancia una exigencia ciudadana ${ }^{22}$. De acuerdo con Cunill ${ }^{23}$, su emergencia y posición privilegiada en la agenda internacional fue consecuencia de múltiples factores:

20 Recordando como se dijo anteriormente, que la transparencia no es un elemento natural de las organizaciones.

21 AGUILAR. Op. Cit. p. 23.

22 Ibíd. p. 11.

23 CUNILL, Nuria. Op. cit. (2015) 


\section{- Caída de los autoritarismos}

Por su naturaleza, contraria a la libre circulación de la información, el fin de regímenes autoritarios implicó sin lugar a duda una condición necesaria para la adopción de políticas sobre transparencia en distintos Estados.

\section{- Las necesidades de mercado}

Si bien Cunil| ${ }^{24}$ no demerita el rol del mercado a la hora de hablar sobre transparencia, Aguilar ${ }^{25}$ es bastante más enfático a la hora de señalar que la causa de su creciente importancia en el ámbito nacional e internacional se debió más a factores económicos que políticos. Para este último, la adopción de marcos jurídicos que aseguraran el derecho de acceso a la información y transparencia de las entidades públicas nace a partir del proceso de "globalización de los mercados y de la necesidad de contar con mayor y mejor información sobre su verdadero funcionamiento"26.

A partir de lo anterior se explica, que al menos en sus inicios, algunos de los grandes promotores de la Transparencia hayan sido organismos económicos, como lo son la Organización para la Cooperación y el Desarrollo Económicos (OCDE) o el Banco Mundial, al igual que las ONG vinculadas al mundo empresarial, como lo es Transparencia Internacional, surgida en Alemania e impulsada por organizaciones empresariales reconocen en la transparencia y acceso a la información una conexión directa con la lucha contra la corrupción y las oportunidades económicas que las empresas puedan tener ${ }^{27}$

\section{- Reforma del Estado: La Nueva Gestión Pública}

Mientras que Cunill ${ }^{28}$ considera como posible y en un plano más limitado el que las reformas al Estado hubieran influido en la valorización de la transparencia, para Vergara dichas reformas, impulsadas por las ideas de la Nueva Gestión Pública, vieron en la Transparencia un mecanismo de control adecuado (aunque no suficiente por sí mismo), a la hora de enfrentar los desafíos planteados por un modelo de gestión y organización que tiene como consecuencia "la aparición de multitud de organismos y comisiones de carácter técnico, semiautónomos del gobierno central, encargados de asuntos y problemas específicos, los cuales se ponen bajo la responsabilidad de un gerente" 29 .

\section{CHILE REACCIONA ANTE EL CONTEXTO INTERNACIONAL: Cómo se gestó la Ley sobre Acceso a la Información Pública en Chile}

La Ley $N^{\circ} 20.285$ sobre Acceso a la Información Pública es una normativa relativamente nueva y reciente (recordando que esta se promulga el año 2008 y entra en vigor en 2009; sin embargo, no es el primer acercamiento que Chile posee hacia una mayor accesibilidad de información y rendición de cuentas a la ciudadanía. La primera "aproximación" que

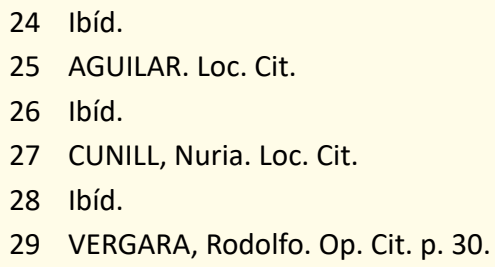


existió en Chile, respecto a la probidad, transparencia y modernización en los procesos del aparataje estatal, se da con la creación de la Comisión Nacional de Ética Pública en 1994º. Esta Comisión tuvo por objeto:

a) "Estudiar la legislación nacional vigente en materia de probidad funcionaria con el objeto de proponer perfeccionamientos o reformas.

b) Analizar el funcionamiento de los mecanismos de control y fiscalización existentes con el objeto de proponer perfeccionamientos o reformas.

c) Sugerir eventuales perfeccionamientos o reformas de la legislación vigente en torno al financiamiento de los partidos políticos y las campañas electorales.

d) Evaluar la reglamentación vigente en materia de contratos y licitaciones del Estado con el objeto de proponer eventuales perfeccionamientos y reformas destinados a garantizar la transparencia de los procedimientos.

e) Revisar la legislación vigente respecto a los conflictos de interés incompatibles entre sí de quienes ejerzan funciones públicas con el objeto de proponer perfeccionamientos o reformas.

f) Sugerir políticas que tienda a cautelar los intereses públicos y a prevenir y sancionar el uso indebido de influencias.

g) Estudiar los delitos que dicen relación con la ética pública configurados en la legislación vigente y hacer un catastro de aquellos actos reñidos con la ética pública que no estén tipificados como delitos ${ }^{\prime \prime 31}$.

Como indica, se buscó que distintos expertos, académicos y autoridades sugiriesen, en un plazo de cien días, propuestas para mejorar aquellas falencias detectadas.

De tal modo, para efectos de esta investigación y sobre aquellos aspectos relacionados con el segundo objetivo, las sugerencias emanadas del Informe elaborado por la comisión fueron las siguientes:

\section{a. Control y prevención de la corrupción:}

Uno de los propósitos de la comisión fue generar propuestas relativas al control ejercido por la ciudadanía, respecto de los procesos y gestión del Estado. Para esta comisión era esencial hacer operativos los mecanismos y prácticas, aplicables a la sociedad civil, y que tuviesen como norte vigilar y evaluar de manera continua las actividades de los agentes del Estado y sus instituciones. Además, este control debía ser ininterrumpido.

Cabe señalar, también, que hasta 1996 no era obligatorio para los organismos públicos rendir cuentas públicas y periódicas de sus objetivos, proyectos, actividades y resul-

30 PRECHT R., Alberto. El derecho de acceso a la información en Chile: historia e implementación. Tesis (Memoria de título para optar al grado de Licenciado de Ciencias Jurídicas y Sociales). Santiago, Chile, Universidad de Chile, Facultad de Derecho, 2015. [En línea]. [Fecha de consulta: 30 de junio 2020]. pp. 6-11

31 Decreto $N^{\circ}$ 423. Crea la Comisión Nacional de Ética Pública. Diario Oficial de la República de Chile. Santiago, 18 de abril de 1994. p. 1. 
tados, y por ello la comisión sugirió una legislación sobre el acceso de la ciudadanía a la información pública que propendiera, entre otras cosas, a un control constante y público.

Finalmente, con esto se buscaría forjar, o bien, reavivar en la ciudadanía el sentimiento y la intención de cautelar o fiscalizar los asuntos públicos y los intereses generales ("bien común"), disminuyendo así el sentimiento de indiferencia, apatía y desconfianza en el quehacer público.

Por ello, el control social se traduciría en una combinación de acceso a la información para la ciudadanía, compromiso y organización social, y una participación vinculante e incidente en las decisiones públicas.

\section{b. Ley de Acceso a la Información Pública}

Para la comisión, solo una ciudadanía suficientemente informada de la gestión pública podía ejercer un control activo en esta área. Por ello, se consideró que la transparencia, sistematicidad y fluidez de la información pública sería un objetivo social prioritario. Para tal efecto, estimó necesario legislar sobre el acceso a la información pública (documentos, actas e informes sobre materia pública, entre otros) y, ¿qué debía contener esta legislación?

En primer lugar, debía detallar los procedimientos o etapas para lograr acceder a la información, junto con una definición clara de los plazos para este proceso. Por otro lado, y en relación con la información reservada o delicada, tendría que puntualizar en qué casos o excepciones se podría recurrir a ese criterio para denegar el acceso a la misma y, en último lugar, también debería definir los mecanismos de resolución ante discordancias entre la ciudadana que efectuase la solicitud de acceso a la información y el organismo incumbente.

Finalmente, con la aprobación de esta ley, se buscaba fortalecer el rol de los medios de educación social ligados a difusión y escrutinio de la actividad de los poderes del Estado, a fin de dar a conocer de manera efectiva y clara el desempeño de los organismos públicos, permitiendo de todos modos que, si existía alguna duda por parte de la ciudadanía, esta fuera dada a conocer mediante canales establecidos.

La mayor contribución que significó el trabajo de esta comisión fue poner en la agenda de gobierno el interés por la transparencia y la probidad en los actos administrativos del Estado, razón por la cual se envía al parlamento diversos proyectos de ley que pretendían abarcar estos tópicos nuevos para la Administración Pública chilena.

Surge de esta contribución, en el año 1999, la Ley 19.653 sobre "Probidad Administrativa aplicable a los órganos de Administración del Estado" ${ }^{32}$. Esta ley abarcaría, entre algunos tópicos, lo discutido en el informe de la Comisión Nacional de Ética Pública respecto a la probidad; sin embargo, y dado a que de manera interna el proyecto inicial presentaba contradicciones respecto de cómo tratar la información, como, por ejemplo, el hecho de que indicase a grandes rasgos: 
A más de una década de la Ley de Transparencia: sus inicios y aproximaciones a las Fuerzas...

"(...) en su artículo 7 inciso 2 como Principio General de la Administración del Estado que "... Las actuaciones de los órganos de la Administración del Estado son públicas, salvo las excepciones que establezca la ley..." y en su artículo 21 en su primer numeral como conducta contraria a la probidad administrativa el "Negar información o documentación que haya sido solicitada en conformidad a la ley"33.

Por este tipo de contradicciones se dio lugar a una serie de informes elaborados por las Comisiones de Constitución de la Cámara de Diputados y de Senadores, quienes tras una extensa discusión legal (de años) respecto de qué información sería considerada pública y accesible a la ciudadanía y cuál no, finalmente aprobarían y sería así publicada la ley ${ }^{34}$ en 1999.

Si de hitos importantes respecto de la importancia de sentar la transparencia como un elemento fundamental dentro de los ejercicios plenos de la democracia y el acceso a la información se trata, en Chile es crucial el caso "Claude-Reyes".

Para contextualizar y según Sousa, en el año 1998 existió en el citado país una iniciativa de la empresa forestal extranjera Trillium de explotar una cantidad -no menor- de 250 mil hectáreas de lenga en la zona austral, lo que tendría presumiblemente efectos negativos a nivel ambiental. Ante esto, representantes de la sociedad civil y política, como organizaciones medioambientales y parlamentarios, pidieron al Comité de Inversiones Extranjeras que se les facilitara información relativa al impacto y consecuencias de tal actividad en el ecosistema y el medioambiente, lo que les fue denegado. El agravante en este caso particular resulta en las constantes negativas por parte del Estado chileno de facilitar antecedentes respecto de este proyecto, motivo por el cual estos representantes decidieron recurrir a instancias superiores, llegando así a la Corte Interamericana de Derechos Humanos (Corte IDH), quien condenó en el año 2006 al Estado chileno por negarse a entregar los datos requeridos y transgrediendo así el derecho de acceso a la información ${ }^{35}$.

Sousa comenta que el fallo de la Corte tuvo dos elementos importantes que posteriormente debían ser considerados dentro del ejercicio de la gestión pública: además de reconocer el derecho de acceso a la información, exige al Estado a cuestionarse la obligación de otorgar los mecanismos o prácticas adecuadas y pertinentes de acceso a la información para todo aquel interesado en disponer de ella sin mayores cuestionamientos ${ }^{36}$. En este sentido, Contreras expone que la Corte IDH tuvo como uno de los fundamentos para la resolución de este caso, la estimación de que todas las actuaciones del Estado deben estar conducidas por el principio de publicidad y transparencia, puesto que faculta a las personas que estén bajo su jurisdicción, el ejercicio pleno de un control social que les permita

33 Ibíd. p. 23.

34 Para efectos de esta investigación, se precisa en el Artículo 7 de este cuerpo normativo, que las únicas causales por las cuales se podrá negar el acceso o entrega de información pública, será la reserva o el secreto, los cuales se encontrarán debidamente definidos en las disposiciones legales o reglamentarias correspondientes, o bien que su divulgación o conocimiento "afecte la seguridad de la nación o el interés nacional", y existirán disposiciones legales que definirán los casos en los cuales la documentación se considera secreta o reservada, los cuales obrarán en pro de los órganos estatales. SOUSA O., José. Op. Cit. pp. 14-15. Ibíd. 
"cuestionar, indagar y considerar" qué nivel de logro se da en el desempeño de la función pública. Ello, por tanto, presiona -en general- a la Administración Pública, a ser consciente de entender esta nueva realidad, y adaptarse a ella ${ }^{37}$.

Por otro lado, otro hito destacable dentro de la evolución del sistema normativo chileno, basado en el interés de volver accesibles a la ciudadanía la información pública, es la dictación de la Ley 19.880, que establece Bases de los Procedimientos Administrativos que rigen los actos de los Órganos de la Administración del Estado. En el artículo 16 de este cuerpo legal, se determinan como principios rectores la publicidad y la transparencia de los actos, indicando que los procedimientos administrativos serían ejecutados con transparencia, a fin de promover el conocimiento de los contenidos, decisiones y trámites involucrados en él, salvo aquellas excepciones determinadas en las demás leyes o reglamentos.

Para Pretch ${ }^{38}$, esta normativa reviste de vital importancia dentro de la modernización del Estado y la incorporación del concepto de "transparencia" en las gestiones gubernamentales, ya que después de la aprobación de esta norma, se colocan en el ámbito público y de fiscalización por parte de la ciudadanía, diversos escándalos que implicaban corrupción dentro del Estado, y entre los cuales se pueden mencionar el "Caso Coimas", "Caso Sobresueldos" y el "Caso MOP-GATE" ${ }^{39}$, lo cual tendría un impacto en la labor vigilante de los chilenos interesados en el desempeño y el trabajo del sector político.

Así, sucesivamente la transparencia, publicidad y probidad en el ejercicio de la función pública toma una relevancia más notoria y protagonista, de modo que en el año 2005 se da lugar a una Reforma Constitucional, que posteriormente vería concretizada esta modificación, con la promulgación y entrada en vigor de la Ley 20.050. Este cambio en la Carta Magna se produjo en el gobierno del entonces presidente Ricardo Lagos, tras un importante consenso entre las principales fuerzas políticas ${ }^{40}$, y donde se buscaba generar una modificación a la Constitución Política de 1980 (también abreviada como CPR), tales como la reforma al Tribunal Constitucional, al sistema electoral binominal y a la designación de senadores vitalicios, entre otras, buscando sentar las bases del establecimiento democrático en el país.

37 CONTRERAS V., Pablo. Secretos de Estado. Transparencia y Seguridad Nacional. Santiago, Chile. Editorial Legal Publishing, 2014. pp. 28-30.

38 PRECHT R., Alberto. Op. Cit. pp. 61-65.

39 Tres casos de corrupción de interés: a) Caso Coimas: se da lugar en el año 2002, y consiste en que surge una denuncia por parte del empresario Carlos Filippi, quien informa haber pagado 15 millones de pesos a Patricio Tombolini, subsecretario de Transportes de tal periodo, a fin de que se pusiera en funcionamiento una planta de revisión técnica en Rancagua, teniendo como involucrado a diversos diputados. b y c) Caso Sobresueldos y MOP-GATE: se da durante el gobierno de Ricardo Lagos (200-2006), y consiste en que el Ministerio de Obras Públicas (MOP) paga sobresueldos a funcionarios por trabajos que no se habrían llevado a cabo, mientras que la empresa Gestión Ambiental y Territorial Sociedad Anónima (GATE S.A.) habría recibido pagos infundados por las autopistas concesionadas y sus proyecciones desde 1997, desde lo cual se habría concluido un fraude total al Fisco por 1.253 millones de pesos

40 DÍAZ DE VALDÉS, José Manuel. La reforma constitucional del año 2005: contexto, impacto y tópicos pendientes [online]. 2009, [citado 2020-07-25] en Actualidad Jurídica (UDD), Año X, № 20: pp. 35-69. Disponible en: https://derecho.udd.cl/centro-justicia-constitucional/files/2015/08/La-reforma-constitucional-del-a\%C3\%B1o-2005.pdf 
Tanto Vivanco ${ }^{41}$ como Pretch ${ }^{42}$ concuerdan en señalar que la probidad dentro de las acciones del Estado, junto con otorgar la calidad de público, a los actos, resoluciones, disposiciones y cualquier otra acción similar emanada de los órganos estatales son elementos coincidentes de la transparencia. También señala que una ley de quórum calificado será la única que podrá definir qué documentos serán considerados reservados o secretos. De este modo la CPR fija un elemento clave para un Estado de derecho. Asimismo, este cambio constitucional reviste especial significancia pues, como plantea Quintana, determina un impacto directo e inmediato en el vínculo entre la ciudadanía y el Estado, dado que obliga a éste a generar una "nueva relación" con los ciudadanos ${ }^{43}$. Se determina en la Carta Magna, eso sí, ciertos alcances de dicha publicidad.

Tres años más tarde, también en un mes de agosto, se promulga la Ley 20.285 sobre acceso a la información pública (puesta en vigencia el año 2009), permitiéndole a la legislación chilena dar un nuevo paso en lo que refiere a transparencia, llenando así importantes vacíos en la materia, y concretando un capítulo en la historia de la probidad y transparencia en el país, ante las diversas interpretaciones que se le daban en la práctica ${ }^{44}$. De esta manera, se inicia una nueva etapa para Chile al respecto, en la cual el gobierno de la presidenta Michelle Bachelet, quien promulgó esta ley, esperaba que se afianzara "la cultura democrática", confiando en que "cuando hay transparencia, el Estado se acerca a los ciudadanos" 45 .

\section{LEY N²0.285 SOBRE ACCESO A LA INFORMACIÓN PÚBLICA}

Junto con definir e instaurar en la legislación una serie de principios asociados a la transparencia de la información, la Ley 20.285 entrega las directrices de los procedimientos para solicitar información y determina cuál es la información que debe ser puesta a disposición por parte de los organismos de la Administración del Estado, cuáles de éstos están en la obligación de hacerlo, y cuáles pueden mantenerla en reserva o secreto y bajo qué circunstancias. Así, se estipula que toda persona tiene derecho a solicitar y recibir información de los órganos de la Administración del Estado, la cual comprende datos contenidos en actos, resoluciones, actas, expedientes, contratos y acuerdos, así como toda aquella información que se elabore con presupuesto público. Este mandato articula las bases de la regulación sobre acceso a la información pública, sentando la responsabilidad de la observancia de su cumplimiento tanto en el control interno de los propios órganos de la Administración del Estado, así como en Consejo para la Transparencia y la Contraloría General de la República.

41 VIVANCO M., Ángela. Transparencia de la función pública y acceso a la información de la administración del Estado: una normativa para Chile, 2008. Revista Chilena de Derecho, [En línea]. Vol 35 n.2. pp.371-391, 2008 [Fecha de consulta: 15 de mayo 2020]. Disponible en: https://scielo.conicyt.cl/scielo.php?script=sci_arttext\&pid=S0718-34372008000200011. ISSN: 0718-3437. pp. 385-386.

42 PRECHT R., Alberto. Op. Cit. pp. 65-77.

43 QUINTANA B., Augusto. Reformas a las bases de la institucionalidad: Entre lo superfluo, el contrabando y la inocencia. Revista de Derecho Público, 2006, no 68, pp. 160-185.

44 Ibíd.

45 EL MOSTRADOR. Bachelet promulga ley de Transparencia y Acceso a Información del Estado. El Mostrador [en línea], 11 agosto, 2008. [Fecha de consulta: 20 de julio de 2020]. Disponible en: https://www.elmostrador.cl/noticias/pais/2008/08/11/bachelet-promulga-ley-de-transparencia-y-acceso-a-informacion-del-estado/ 


\subsection{Transparencia Activa}

Uno de los primeros títulos de la Ley de Transparencia versa sobre la Transparencia Activa. Esta dimensión de la ley instala un deber proactivo con el cual deben trabajar los organismos públicos, de manera que los sitios electrónicos de los mismos mantengan constantemente a disposición de las personas todos los actos y documentos que han sido publicados en el Diario Oficial y que se vinculen con las funciones, competencias y responsabilidades de esa institución.

De esta manera, se define una serie de elementos de cada organismo, que deben permanecer a disposición del público en sus sitios electrónicos respectivos. Cuando los órganos y/o servicios no cuenten con un sitio web propio, deben mantener esta información publicada en el portal electrónico del ministerio del cual dependen o se relacionen con el Ejecutivo. Los datos que forman parte de esta exigencia son:

1. Estructura orgánica.

2. Facultades, funciones y atribuciones de cada unidad.

3. Marco normativo aplicable.

4. Personal a planta, a contrata y a honorarios, con sus respectivas remuneraciones.

5. Contrataciones para suministro de bienes, prestación de servicios y ejecución de distintos apoyos (asesorías, consultorías, etc.).

6. Transferencias de fondos públicos que efectúan a todo tipo de destinatario.

7. Actos y resoluciones que tengan efectos sobre terceros.

8. Trámites y requisitos necesarios para tener acceso a los servicios que presta el órgano.

9. Diseño, montos asignados y criterios de acceso a programas de subsidios y beneficios que ofrece el órgano, junto con nóminas de beneficiarios de programas sociales en ejecución.

10. Mecanismos de participación ciudadana, cuando corresponda.

11. Datos sobre el presupuesto asignado e informes sobre la ejecución de este.

12. Resultados de auditorías al ejercicio presupuestario del órgano, y las aclaraciones relativas, en su caso.

13. Entidades en las que el órgano tenga participación, representación e intervención.

14. Vínculo al portal de compras públicas, en adquisiciones sometidas a ese sistema.

15. Registros indicados por la Ley 19.862 , en el caso de transferencias de fondos públicos que regule dicha ley.

\subsection{Principios de la ley}

Entre estos principios se define e instaura entre los primeros artículos de la legislación el principio de transparencia de la función pública, mismo que busca respetar y caute- 
lar la publicidad de los actos, resoluciones, procedimientos y documentos de la Administración estatal. Posteriormente, en el artículo 11 del Título IV, se establece que el derecho de acceso a la información a los órganos de la Administración del Estado reconoce los principios de: relevancia, de la libertad de información, de apertura o transparencia, de máxima divulgación, de divisibilidad, de facilitación, de la no discriminación, de la oportunidad, del control, de la responsabilidad y de la gratuidad. La definición de cada uno de ellos puede expresarse en la siguiente gráfica:

Tabla $\mathbf{N}^{\circ} 2$

\section{Principios del derecho al acceso a la información pública}

\begin{tabular}{|c|c|}
\hline Principio & Definición \\
\hline De la relevancia & $\begin{array}{l}\text { Relevancia de toda la información que posean los órganos de la } \\
\text { Administración del Estado. }\end{array}$ \\
\hline $\begin{array}{l}\text { De la libertad de } \\
\text { información }\end{array}$ & $\begin{array}{l}\text { Toda persona tiene de derecho a acceder a la información que posean } \\
\text { los órganos de la Administración del Estado (con las excepciones } \\
\text { establecidas en leyes de quorum calificado). }\end{array}$ \\
\hline $\begin{array}{l}\text { De apertura o } \\
\text { transparencia }\end{array}$ & $\begin{array}{l}\text { Toda la información de los órganos de la Administración del Estado se } \\
\text { presume pública, exceptuando las limitaciones señaladas por ley. }\end{array}$ \\
\hline $\begin{array}{l}\text { De máxima } \\
\text { divulgación }\end{array}$ & $\begin{array}{l}\text { Se debe proporcionar la información en los términos más amplios } \\
\text { posibles, excluyendo las excepciones legales. }\end{array}$ \\
\hline De la divisibilidad & $\begin{array}{l}\text { Si un acto administrativo contiene información que puede ser conoci- } \\
\text { da e información que debe denegarse en virtud de causa legal, se dará } \\
\text { acceso a la primera y no a la segunda. }\end{array}$ \\
\hline De facilitación & $\begin{array}{l}\text { Los mecanismos de acceso a la información deben facilitar el ejercicio } \\
\text { del derecho, excluyendo exigencias que puedan obstruirlo. }\end{array}$ \\
\hline $\begin{array}{l}\text { De la no } \\
\text { discriminación }\end{array}$ & $\begin{array}{l}\text { La información debe entregarse a todas las personas que la soliciten, } \\
\text { en igualdad de condiciones y sin hacer distinciones arbitrarias ni } \\
\text { exigencias de expresión de causa. }\end{array}$ \\
\hline De la oportunidad & $\begin{array}{l}\text { Los órganos de la Administración del Estado deben brindar respuestas } \\
\text { a las solicitudes de información dentro de los plazos legales, con la } \\
\text { mayor celeridad posible. }\end{array}$ \\
\hline Del control & $\begin{array}{l}\text { El cumplimiento de las normas que regulan el derecho de acceso a la } \\
\text { información será objeto de fiscalización permanente, y las resolucio- } \\
\text { nes sobre dicha materia son reclamables ante un órgano externo } \\
\text { (Consejo para la Transparencia). }\end{array}$ \\
\hline $\begin{array}{l}\text { De la } \\
\text { responsabilidad }\end{array}$ & $\begin{array}{l}\text { El incumplimiento de las obligaciones estipuladas por la ley da lugar a } \\
\text { las sanciones determinadas por la misma. }\end{array}$ \\
\hline De gratuidad & $\begin{array}{l}\text { El acceso a la información de órganos de la Administración del Estado } \\
\text { es gratuito. }\end{array}$ \\
\hline
\end{tabular}

Fuente: Elaboración propia en base a la Ley 20.285 
El derecho de acceso a la información plantea que los organismos públicos tienen el deber de entregar la información que sea solicitada por alguna persona, reconociendo el derecho de esta de acceder a los datos relativos a actos administrativos, resoluciones, actas e informes, expedientes, contratos y acuerdos, y a toda información que se elabore con presupuesto público, exceptuando aquellos casos que la ley estipule.

De acuerdo con ello, y en atención a las solicitudes recibidas, la jefatura o autoridad del órgano de la Administración del Estado debe pronunciarse sobre la solicitud recibida, ya sea entregando la información o negándose a ello, en un plazo límite de veinte días hábiles desde la recepción de la solicitud de datos, el cual podría extenderse por otros diez días hábiles en caso de que, excepcionalmente, existan circunstancias que dificulten la entrega de información. En el supuesto de que se diera esta situación, el órgano responsable deberá informar al solicitante sobre la demora en la entrega de los datos, antes del vencimiento del plazo, la prórroga y sus fundamentos.

\subsection{Plazos}

La jefatura del órgano de la Administración del Estado al que haya recibido una solicitud de información, deberá pronunciarse sobre la misma, entregándola o denegándola, en un plazo máximo de veinte días hábiles, considerados desde la recepción de una solicitud que cumpla con las exigencias de la ley. Dicho plazo puede prorrogarse en circunstancias excepcionales que compliquen la entrega de información, por otros diez hábiles. Cuando esto ocurra, se le debe informar al solicitante sobre el vencimiento del plazo, la prórroga y los fundamentos de la misma.

Una vez vencido este plazo, y en caso de no recibir respuesta por parte del órgano de la Administración del Estado, el solicitante tendrá derecho a recurrir ante el Consejo para la Transparencia, solicitando amparo a su derecho de acceso a la información, presentando un reclamo dentro de los próximos quince días contados desde la notificación de la denegación de acceso a la misma.

En caso de que el Consejo para la Transparencia resuelva que la información solicitada es de carácter público, la información, dichos, antecedentes y actuaciones relativas también serán públicas. De esta forma, el reclamante podrá acceder a la información solicitada una vez que esté ejecutoriada la resolución que declare que dichos datos son públicos.

\subsection{Qué es público}

En ese sentido, es importante acotar lo que la Ley 20.285 define como público y por tanto, objeto de transparencia de la función pública: "los actos y resoluciones de los órganos de la Administración del Estado, sus fundamentos, los documentos que les sirvan de sustento o complemento directo y esencial, y los procedimientos que se utilicen para su dictación", exceptuando aquellos casos que la misma ley establece, además de las explicitadas en otras leyes de quorum calificado. Siguiendo este precepto, se puntualiza que toda información elaborada con presupuesto público y toda aquella que sea poder de los órganos de la Administración estatal es pública, independientemente de su origen, fecha de creación, formato, soporte, clasificación o procesamientos, exceptuando, claramente, las distinciones que la misma ley señala. 


\subsection{Aplicabilidad de la ley}

Desde la aplicación de esta ley, los ministerios, intendencias, gobernaciones, gobiernos regionales, municipalidades, Fuerzas Armadas, Fuerzas de Orden y de Seguridad Pública, y los órganos y servicios públicos creados para el cumplimiento de la función administrativa, deben seguir las disposiciones de la ley, mientras que las autoridades a cargo de dichos organismos deben dar estricto cumplimiento al principio de transparencia de la función pública. En tanto, la Contraloría General de la República y el Banco Central deben regirse por las disposiciones explícitamente señaladas en la Ley 20.285, y a las de sus respectivas leyes orgánicas que se relacionen con esta materia.

\subsection{Excepciones}

La entrega de información puede denegarse cuando la solicitud se vincule a documentos o antecedentes que puedan afectar los derechos de terceros, la autoridad o jefatura del órgano de la Administración del Estado requerido. Cuando esto ocurra, se debe notificar en un plazo de dos días hábiles al solicitante que se denegará la entrega de datos.

Adicionalmente, se puede negar la entrega de información en virtud de las causales de secreto o reserva, relacionadas a situaciones en las que:

- La publicidad, comunicación o conocimiento afecte el debido cumplimiento de las funciones del órgano requerido.

- La publicidad, comunicación o conocimiento afecte los derechos de las personas, especialmente sobre su seguridad, salud, vida privada, o derechos económicos.

- La publicidad, comunicación o conocimiento afecte la seguridad de la Nación, particularmente si se refiere a la defensa nacional o la mantención del orden público o la seguridad pública.

- La publicidad, comunicación o conocimiento afecte el interés nacional, especialmente en lo referido a la salud pública o las relaciones internacionales y los intereses económicos o comerciales del país.

- Cuando se trate de información que hayan sido declarados reservados o secretos por una ley de quorum calificado.

Asimismo, se especifica que el carácter secreto o reservado será indefinido en cuanto a documentos y actos que, en el ámbito de la defensa nacional, establezcan la planificación militar o estratégica, y de aquellos cuyo conocimiento pudiesen afectar la integridad territorial de Chile; la interpretación o el cumplimiento de un tratado internacional suscrito por Chile en materia de límites; la defensa internacional de los derechos de Chile; y, la política exterior del país de manera grave.

\subsection{Consejo para la Transparencia (CPLT)}

En esa línea, y con el fin de promover la transparencia de la función pública, fiscalizar el cumplimiento de las normas sobre transparencia y publicidad de la información de los órganos de la Administración del Estado, y garantizar el derecho de acceso a dicha información, se crea con esta ley el Consejo para la Transparencia (CPLT), una corporación 
autónoma de derecho público con la capacidad de solicitar apoyo de los distintos órganos del Estado para el ejercicio de sus atribuciones.

El consejo, entre otras funciones, tiene la atribución de atender y resolver los reclamos por denegación de acceso a la información, mismas que deben presentarse en un plazo de quince días contados desde la notificación de la denegación de información. No obstante lo anterior, y en contra de una resolución del consejo que deniegue el acceso a la información, es posible proceder con un reclamo de ilegalidad ante la Corte de Apelaciones del domicilio del reclamante.

\section{FUERZAS ARMADAS Y TRANSPARENCIA}

Una de las complejidades fundamentales del derecho de acceso a la información pública es la relación de la transparencia y la seguridad nacional, ambas políticas institucionales esenciales para el mantenimiento y desarrollo de un Estado Liberal y Democrático ${ }^{46}$.

El desarrollo del Derecho de acceso a la información pública en Chile ha implicado un avance para terminar con el secretismo del actuar Estatal. Ante este nuevo desafío, las instituciones castrenses, al igual que otros órganos del Estado, han tenido que aplicar reingeniería en sus procesos de gestión, con el objetivo de transparentar las materias dispuestas por esta ley e ir más allá de la rendición de cuentas de carácter voluntario, mediante reportes o balances organizacionales anuales o las diversas materias publicadas, a través del tiempo en los libros de la Defensa Nacional ${ }^{47}$, y, a su vez, enfrentar los dilemas propios de la publicidad y restricción de la información en pos de la seguridad.

A continuación, se presentarán las particularidades de las condiciones de reserva en las FF.AA., como también los principales límites del derecho de acceso a la información pública en el ámbito de defensa que usualmente se usan para denegar información, los cuales se condicen con la reserva o secreto que se encuentran establecidos, por ejemplo, en la CPR, la LT, el Código de Justicia Militar (CJM) y la Ley de Inteligencia, entre otras particularidades, con el fin de describir el panorama general de la transparencia en las FF.AA.

\subsection{Condiciones de reserva dentro de las Fuerzas Armadas}

De manera general, las FF.AA., a diferencia de otros organismos públicos, gestionan información de índole militar "que es inevitablemente valiosa para los Estados y constituye una reserva esencial en la protección de la soberanía"48. Es por esto que estas instituciones

46 GUERRERO Gutiérrez, Eduardo. Transparencia y seguridad nacional. Cuadernos de transparencia, Instituto Federal de Acceso a la Información y Protección de Datos. México [En línea]. 2010, [Fecha de consulta: 15 de julio de 2020]. Disponible en: http://www.itei.org.mx/v3/micrositios/diplomado/2016/ocotlan/anexos/ presentaciones/iv_-_1a18_-_transparencia_y_seguridad.pdf. ISBN: 14p. 1978-968-5954-56-3. p. 9.

47 Los Libros de la Defensa del 1997, 2002, 2010 y 2017, se encuentran disponibles en la página web del Ministerio de Defensa y dan cuenta de diferentes áreas del quehacer de la defensa, como también de las instituciones pertenecientes a esta.

48 SMITH, Rhona. 2005. Citado en GARCÍA, Gonzalo y CONTRERAS, Pablo. "Derecho de Acceso a la Información en Chile: Nueva Regulación e Implicancias para el Sector de la Defensa Nacional", en Estudios Constitucionales [En línea]. Vol. 7, No. 1. pp. 137-175, 2009 [Fecha de consulta: 08 de mayo 2020]. Disponible en: https://www.pcontreras.net/uploads/9/6/2/1/9621245/daip_cecoch.pdf. ISSN: 0718-0195. p. 53. 
A más de una década de la Ley de Transparencia: sus inicios y aproximaciones a las Fuerzas...

deben resguardar parte de su información, con la finalidad de proveer de manera óptima el bien público de la defensa ${ }^{49}$, pero en este contexto, Guerrero concuerda que, con frecuencia, se restringe infundadamente información pública debido a que presumiblemente su publicidad causaría un daño a la seguridad nacional ${ }^{50}$.

En este contexto, si se hace una revisión a la historia de las FF.AA., se puede evidenciar que las condiciones de reserva fueron interpretadas ampliamente bajo el gobierno militar, puesto que la concepción de la seguridad nacional ${ }^{51}$ se entendía en términos amplísimos, y esta, no siempre coincidió adecuadamente con los intereses de la defensa nacional y su función. Hecho evidente, ya que la literatura coincide que "los gobiernos débiles han demostrado una tendencia a definir su seguridad nacional como protección del gobierno frente a amenazas internas tales como la guerrilla, la revuelta, el crimen organizado o los golpes de estado"52, pero esta tendencia fue abandonada con la transición democrática y reforma constitucional, lo que conlleva una estabilidad que asegura que la seguridad nacional se refiere a protección frente a amenazas externas.

Es por este motivo que las FF.AA. tuvieron que adaptarse a los nuevos estándares y desafíos que impone la ley, con el fin de considerar información o antecedentes que por un lado afectan la función de la defensa, de los que no implica un riesgo en su divulgación, ya que las instituciones de las FF.AA., antes de la LT, "tenían por regla general que la información por disposición reglamentaria (Decretos Supremos), como de la propia autoridad militar que las dictaba, tuvieran el carácter de reservadas o secretas, por lo que la regla general era su no publicidad y/o la entrega o acceso restrictivo, no solo a la ciudadanía, sino que también internamente" ${ }^{\prime \prime 3}$.

Esto sin duda conformaba una cultura del secretismo que iba más allá del presentado en los demás órganos públicos, ya que en las FF.AA. existieron ocasiones en que no se ponderaba realmente qué materias eran motivo de resguardo y cuáles no; por ejemplo, una disposición que daba cuenta de la realización de actividades deportivas en una institución castrense, hace unos años era tratado como información reservada, pero en la actualidad no responde a ningún ámbito de resguardo de la información ${ }^{54}$. Es por estos motivos que las condiciones de reserva de las FF.AA., están ligadas a factores propios de su historia, como también a la compleja relación existente entre la "transparencia y acceso a la información pública" y la función de las instituciones de la Defensa.

49 La Defensa Nacional, es considerado un bien público puro, ya que no es excluyente en su uso, es decir cualquiera se beneficia y no presenta rivalidad en el consumo, ya que el uso de este bien por un sujeto, no afecta el uso de un tercero. STIGLITZ, Joseph E. La Economía del Sector Público. $3^{\circ}$ edición, Barcelona, España, Antoni Bosh editor, 2000. p. 95.

50 GUERRERO Gutiérrez, Eduardo. Loc. Cit.

51 Seguridad de la Nación y seguridad nacional se diferencian, ya que este último tiene alcances que van más allá de la a protección de la seguridad externa del Estado amparando en el pasado las acciones ejecutadas en el gobierno militar. A diferencia del primer concepto, que fue introducido en la reforma de CRP del 2005 y que se ve reflejada en el artículo 24 inciso $2^{\circ}$, como también responden a un conjunto de responsabilidades democráticas para sostener la seguridad. CONTRERAS, Pablo. Loc. Cit.

52 GUERRERO. Loc. Cit.

53 NOVOA, Hernán. Asesor del Departamento de Transparencia y Lobby del Ejército, da cuenta del panorama del Ejército de Chile, previo a las legislaciones actuales sobre Transparencia.

54 lbíd. 


\subsection{Desde la CPR hasta la Ley de Inteligencia: restricciones a la Ley de Transparencia}

Como se ha expuesto, las instituciones que integran la defensa nacional poseen informaciones propias de su gestión que pueden comprometer, por ejemplo, la seguridad de la nación, causal amparada por la propia CPR y LT. Es por esto que a continuación, se presentarán las principales restricciones del acceso a la información pública aplicable a las FF.AA., mediante reserva o secreto, comenzando desde la CPR, la LT, el Código de Justicia Militar (CJM), como también la Ley $\mathrm{N}^{\circ} 19.974$, Sobre el Sistema de Inteligencia del Estado y Crea la Agencia Nacional de Inteligencia, también llamada Ley de Inteligencia, entre otras peculiaridades.

\subsubsection{Constitución Política de la República}

Teniendo presente que el capítulo XI, artículo 101 de la CPR establece que las "Fuerzas Armadas existen para la defensa de la patria y son esenciales para la seguridad nacional' ${ }^{\prime \prime 5}$, es plausible que parte de las gestiones que desarrollan estas instituciones involucran la reserva o secreto, ya que la publicidad puede poner en riesgo, tanto el funcionamiento de dichas instituciones, como también para el Estado y su permanencia ${ }^{56}$, elementos que resguarda la legislación chilena, desde la propia CPR, específicamente su artículo $8^{\circ}$, párrafo $2^{\circ}$, como se presenta a continuación:

"Son públicos los actos y resoluciones de los órganos del Estado, así como sus fundamentos y los procedimientos que utilicen. Sin embargo, sólo una ley de quórum calificado podrá establecer la reserva o secreto de aquéllos o de éstos, cuando la publicidad afectare el debido cumplimiento de las funciones de dichos órganos, los derechos de las personas, la seguridad de la nación o el interés nacional" ${ }^{\prime 5}$.

En este sentido, se puede observar que la CPR establece dos expresiones jurídicamente abiertas o indeterminadas, que se condicen con la seguridad de la nación y el interés nacional ${ }^{58}$, las cuales solo pueden ser definidas caso a caso por los tribunales competentes.

\subsubsection{Ley de Transparencia}

Considerando lo anterior, la LT desarrolla aún más lo expuesto en la CPR, por medio de sus artículos $21^{\circ}$ y $22^{\circ}$, los que consideran cuándo se puede denegar información, como también reconoce ciertas materias reservadas o secretas, que son de carácter indefinido. Para profundizar esto, la LT señala respectivamente en los artículos mencionados, que:

55 CONSTITUCIÓN POLÍTICA DE LA REPÚBLICA DE CHILE. Constitución 1980. Diario Oficial de la República de Chile. Santiago, 17 de septiembre de 2005

56 GARCÍA, Gonzalo y CONTRERAS, Pablo. "Derecho de Acceso a la Información en Chile: Nueva Regulación e Implicancias para el Sector de la Defensa Nacional", en Estudios Constitucionales [En línea]. Vol. 7, No. 1. pp. 137-175, 2009 [Fecha de consulta: 08 de mayo 2020]. Disponible en: https://www.pcontreras.net/ uploads/9/6/2/1/9621245/daip_cecoch.pdf. ISSN: 0718-0195

57 CONSTITUCIÓN POLÍTICA DE LA REPÚBLICA DE CHILE. Op. Cit. Art. N 8.

58 CONTRERAS, P. 2014. Op. Cit. p. 43. 
A más de una década de la Ley de Transparencia: sus inicios y aproximaciones a las Fuerzas...

Art 21, punto 3:

“(...) Cuando su publicidad, comunicación o conocimiento afecte la seguridad de la Nación, particularmente si se refiere a la defensa nacional o la mantención del orden público o la seguridad pública"59.

Art 22:

“(...) Sin embargo, el carácter de secreto o reservado será indefinido tratándose de los actos y documentos que, en el ámbito de la defensa nacional, establezcan la planificación militar o estratégica, y de aquéllos cuyo conocimiento o difusión puedan afectar:

a) La integridad territorial de Chile;

b) La interpretación o el cumplimiento de un tratado internacional suscrito por Chile en materia de límites;

c) La defensa internacional de los derechos de Chile, y

d) La política exterior del país de manera grave ${ }^{60}$.

De lo presentado, se puede evidenciar que, al igual que CPR, la LT, además de consagrar el derecho de acceso a la información pública, también lo limita, en pos del bienestar colectivo, como también reconoce variados conceptos que manifiestan indeterminación, que a la vez aluden a una numerosa cantidad de preceptos legales ${ }^{61}$.

\subsubsection{Código de Justicia Militar}

El CJM, publicado 27 de octubre de 1944, expresa en su Art. 43662, ciertos documentos de carácter secretos, y por tanto pueden limitar el derecho de acceso a la información pública en los siguientes aspectos:

"Se entiende por documentos secretos aquellos cuyo contenido se relaciona directamente con la seguridad del Estado, la Defensa Nacional, el orden público interior o la seguridad de las personas y entre otros:

1. Los relativos a las Plantas o dotaciones y a la seguridad de las instituciones de las Fuerzas Armadas o de Carabineros de Chile y de su personal;

2. Los atinentes a planos o instalaciones de recintos militares o policiales y los planes de operación o de servicio de dichas instituciones con sus respectivos antecedentes de cualquier naturaleza, relativos a esta materia;

59 LEY N² 20.285. Sobre Acceso a la Información Pública. Diario Oficial de la República de Chile. Santiago, 20 de agosto de 2008.

60 Ibíd. Art. $\mathrm{N}^{\circ} 22$.

61 VIVANCO Martínez, Á. Loc. Cit.

62 Este artículo fue incorporado durante el gobierno militar, mediante la Ley $\mathrm{N}^{\circ} 18.667$, de 27 de noviembre de 1987. 
3. Los concernientes a armas de fuego, partes y piezas de las mismas, municiones, explosivos, sustancias químicas y demás efectos a que se refiere la ley $N^{\circ} 17.798$ usados por las Fuerzas Armadas o Carabineros de Chile, $y$

4. Los que se refieran a equipos y pertrechos militares o policiales" ${ }^{\prime 63}$.

Hay que considerar dos puntos importantes de este cuerpo legal: el primero versa en que este código responde al resguardo del secreto militar en el contexto procesal castrense en tiempos de paz y guerra, se ha ampliado a los organismos que tiene la tutela de la Defensa Nacional y Seguridad Interior ${ }^{64}$. El segundo, implica que los puntos que esta norma define como secreto, son más amplios que las cuatro causales establecidas en el artículo 8 de la $\mathrm{CPR}^{65}$ y si bien, esta información puede ser utilizada para determinar capacidades militares o policiales, también presentan grados de indeterminación que dificultan su definición.

\subsubsection{Ley de Inteligencia}

La Ley de Inteligencia, publicada el 2 de octubre del 2004, establece materias secretas, las cuales son señaladas en su artículo $38^{\circ}$ párrafo $1^{\circ}$, presentado a continuación:

"Se considerarán secretos y de circulación restringida, para todos los efectos legales, los antecedentes, informaciones y registros que obren en poder de los organismos que conforman el Sistema o de su personal, cualquiera que sea su cargo o la naturaleza de su vinculación jurídica con éstos. Asimismo, tendrán dicho carácter aquellos otros antecedentes de que el personal de tales organismos tome conocimiento en el desempeño de sus funciones o con ocasión de éstas" ${ }^{\prime 66}$. En este sentido, la información secreta y de circulación restringida va directamente vinculada a la información que comprende el Sistema de Inteligencia del Estado, el que en su artículo $5^{\circ}$, letra c) señala que una de ellas corresponde a las Direcciones de Inteligencia de las Fuerzas Armadas. Es por esto y teniendo presente que parte de la misión de la Agencia Nacional de Inteligencia es "asesorar al Presidente de la República y a los diversos niveles superiores de conducción del Estado, con el objetivo de proteger la soberanía nacional y preservar el orden constitucional" ${ }^{67}$, fin que se enmarca en la Seguridad de la Nacional e Interior del Estado y por ende la divulgación puede tener serias consecuencias en dichos ámbitos.

\section{CONCLUSIÓN}

Los avances en Chile en materia de transparencia y acceso a la información durante los últimos veinte años, son el producto de diversos procesos e hitos históricos, tanto en el ámbito interno como externo.

63 LEY N 18.667. Que agrega el artículo 436 al Código de Justicia Militar de 1944. Diario Oficial de la República de Chile. Santiago, 27 de noviembre de 1987.

64 CONTRERAS. Op. Cit. p. 98.

65 GARCÍA, Gonzalo y CONTRERAS, Pablo. Loc. Cit.

66 LEY N 19.974. Sobre el Sistema de Inteligencia del Estado y crea la Agencia Nacional de Inteligencia. Diario Oficial de la República de Chile. Santiago, 2 de octubre de 2004.

67 Ibíd. Art. N5. 
La consagración del Principio de Probidad y Publicidad de los actos en la Reforma Constitucional del año 2005, así como la implementación de una Política Nacional, un cuerpo jurídico pertinente (Ley 20.285) e iniciativas particulares, enfocadas en desarrollar, evaluar y fortalecer dicho principio en los órganos de la administración del Estado, han implicado diversos desafíos para cada uno de estos, la mayoría de ellos compartidos.

Es claro que, actualmente y respecto a la situación previa a la reforma del año 2005, la situación de las FF.AA. en materia de transparencia ha cambiado radicalmente, puesto que ya no es únicamente por reportes institucionales, libros de la defensa o canales institucionales unilaterales, que las mismas dan cuenta de su actuar. Los solicitantes hoy cuentan con recursos que permiten no solo cuestionar, sino que solicitar pruebas o información específica, pudiendo apelar a instancias superiores distintas a las FF.AA., para eventualmente obligarlas a dar información.

La limitada experiencia del Estado de Chile en materia de transparencia (en la práctica no superior a once años desde la publicación de la Ley 20.285), elementos históricos no menores (Gobierno Militar y Transición), problemas propios de adopción de la transparencia y la visión particular de las FF.AA. en relación a la seguridad nacional (distinta a la de otros órganos no especializados), y por ello se evidencian desafíos permanentes tanto culturales, legales y administrativos, que en un futuro puedan balancear la transparencia y la seguridad nacional, permitiendo destacar los beneficios de ambos principios. 


\section{REFERENCIAS BIBLIOGRÁFICAS}

ACKERMAN, John. Introducción: Más allá del acceso a la información. En: ACKERMAN, John. Más allá del acceso a la información: Transparencia, rendición de cuentas y Estado de derecho. México. Siglo XXI. 2008.

AGUILAR, José Antonio. Transparencia y democracia: Claves para un concierto. México. Instituto Nacional de Transparencia, Acceso o la Información y Protección de Datos Personales. 2015.

ÁlVAREZ Veloso, David. Transparencia y rendición de cuentas en los presupuestos de defensa: del secreto al escrutinio público. Flacso-Chile. Boletín del programa seguridad y ciudadanía No1, 2006.

ARMENGOL, Ángel \& SCHUSTER, Juan. Transparencia y rendición de cuentas en el ámbito municipal. Instituto de la Contaduría Pública. Horizontes de la Contaduría No. 1, Universidad Veracruzana. 2014.

CONSTITUCIÓN POLÍTICA DE LA REPÚBLICA DE CHILE, Constitución 1980. Diario Oficial de la República de Chile. Santiago, 17 de septiembre de 2005.

CONTRERAS V, Pablo. Transparencia y leyes secretas en Chile. Estudios constitucionales [En línea]. 2010, vol.8, n.2 [Fecha de consulta: 17 de julio de 2020], pp. 87124. Disponible en: <https://scielo.conicyt.cl/scielo.php?script=sci_arttext\&pi$\mathrm{d}=$ S0718-52002010000200005\&lng=es\&nrm=iso >. ISSN 0718-5200. http://dx.doi. org/10.4067/S0718-52002010000200005.

CONTRERAS V, Pablo. Secretos de Estado: Transparencia y Seguridad Nacional. Santiago, Chile, Legal Publishing Chile 2014, 56p. ISBN: 978-956-346-562-4

CUNILL, Nuria. La transparencia en la gestión pública: Cómo construir viabilidad. Estado, Gobierno, Gestión Pública. Revista Chilena de Administración Pública No8. 2008

DECRETO N 423. Crea la Comisión Nacional de Ética Pública. Diario Oficial de la República de Chile. Santiago, 18 de abril de 1994.

DÍAZ DE VALDÉS, José. La reforma constitucional del año 2005: contexto, impacto y tópicos pendientes. Actualidad Jurídica, UDD. Año X, № 20: pp. 35-69 [En línea]. 2009, [Fecha de consulta: 25 de julio de 2020]. Disponible en: https://derecho.udd.cl/ centro-justicia-constitucional/files/2015/08/La-reforma-constitucional-del-a\%C3\%B10-2005.pdf

EL MOSTRADOR. Bachelet promulga ley de Transparencia y acceso a Información del Estado. El Mostrador [En línea]. 11 agosto, 2008. [Fecha de consulta: 20 de julio de 2020]. Disponible en: https://www.elmostrador.cl/noticias/pais/2008/08/11/bachelet-promulga-ley-de-transparencia-y-acceso-a-informacion-del-estado/

EL MOSTRADOR. La propuesta del Consejo para la Transparencia para acabar con los secretos del Código de Justicia Militar. El Mostrador [en línea], 30 enero, 2019. [Fecha de consulta: 20 de julio de 2020]. Disponible en: https://www.elmostrador.cl/ 
A más de una década de la Ley de Transparencia: sus inicios y aproximaciones a las Fuerzas...

destacado/2019/01/30/la-propuesta-del-consejo-para-la-transparencia-para-acabar-con-los-secretos-del-codigo-de-justicia-militar/

GARCÍA P, Gonzalo y CONTRERAS V, Pablo. Derecho de Acceso a la Información en Chile: Nueva Regulación e Implicancias para el Sector de la Defensa Nacional, en Estudios Constitucionales [En línea]. Vol. 7, No. 1. pp. 137-175, 2009 [Fecha de consulta: 8 de mayo 2020]. Disponible en: https://www.pcontreras.net/uploads/9/6/2/1/9621245/ daip_cecoch.pdf. ISSN: 0718-0195.

GUERRERO Gutiérrez, Eduardo. Transparencia y seguridad nacional. Cuadernos de transparencia, Instituto Federal de Acceso a la Información y Protección de Datos. México [En línea]. 2010, [Fecha de consulta: 15 de julio de 2020]. Disponible en: http:// www.itei.org.mx/v3/micrositios/diplomado/2016/ocotlan/anexos/presentaciones/ iv_-_1a18_-_transparencia_y_seguridad.pdf. ISBN: 1978-968-5954-56-3.

LEY N 18.667. Que agrega el artículo 436. al Código de Justicia Militar de 1944. Diario Oficial de la República de Chile. Santiago, 27 de noviembre de 1987.

LEY N 18.771. Que modifica Decreto con Fuerza de Ley N5.200, de 1929, del Ministerio de Educación Pública. Diario Oficial de la República de Chile, Santiago, 17 de enero de 1989.

LEY N ${ }^{\circ}$ 19.974. Sobre el Sistema de Inteligencia del Estado y crea la Agencia Nacional de Inteligencia. Diario Oficial de la República de Chile. Santiago, 2 de octubre de 2004.

LEY N²0.285. Sobre Acceso a la Información Pública. Diario Oficial de la República de Chile. Santiago, 20 de agosto de 2008.

NOVOA, Hernán. Entrevista a Asesor Jurídico del Departamento de Transparencia y Lobby del Ejército. Efectuada vía online el 26 de mayo del 2020.

NAESSENS, Hilda. Ética pública y transparencia. XIV Encuentro de Latinoamericanistas Españoles: Congreso internacional, Sep. 2010, Santiago de Compostela, España. México. 2010. p. 121.

PRECHT R., Alberto. El derecho de acceso a la información en Chile: historia e implementación. Tesis (Licenciado de Ciencias Jurídicas y Sociales). Profesor guía: Ana María García Barzelatto. Santiago, Chile, Universidad de Chile, Facultad de Derecho, 2015. 237p. [En línea]. [Fecha de consulta: 30 de junio 2020]. Disponible en http://repositorio.uchile.cl/bitstream/handle/2250/139657/El-derecho-de-acceso-a-la-informaci\%C3\%B3n-en-Chile.pdf?sequence=1

QUINTANA B., Augusto. Reformas a las bases de la institucionalidad: Entre lo superfluo, el contrabando y la inocencia. Revista de Derecho Público, 2006, n68, pp. 160-185.

SOUSA O., José. La experiencia de Chile en la Transparencia y Acceso a la Información: El cambio institucional del Gobierno Central ante las nuevas disposiciones normativas. [En línea]. Tesis (Magíster en Gestión y Políticas Públicas). Profesor guía: Álvaro Vásquez Valdivia. Santiago, Chile: Universidad de Chile - Facultad de Ciencias Físicas y 
Matemáticas, 2010. 108p. [Fecha consulta: 16 de julio 2020] Disponible en http:// repositorio.uchile.cl/handle/2250/102479

STIGLITZ, Joseph. La Economía del Sector Público. $3^{\circ}$ edición, Barcelona, España, Antoni Bosh editor, 2000.

UGALDE, Luis Carlos. Rendición de cuentas y democracia: El caso de México. Instituto Federal Electoral, México. 2002

VERGARA, Rodolfo. La transparencia como problema. Cuadernos de Transparencia. Instituto Federal de Acceso a la información Pública México. 2008

VIVANCO Martínez, Ángela. Transparencia de la Función Pública y Acceso a la Información de La Administración del Estado: Una Normativa para Chile. Revista Chilena de Derecho [En línea]. Vol. 35 n.2. pp. 371-391, 2008 [Fecha de consulta: 15 de mayo 2020]. Disponible en: https://scielo.conicyt.cl/scielo.php?script=sci_arttext\&pi$\mathrm{d}=$ S0718-34372008000200011. ISSN: 0718-3437. 